\title{
Cell density-dependent stimulation of PAI-1 and hyaluronan synthesis by TGF- $\beta$ in orbital fibroblasts
}

\author{
Erika Galgoczi', Florence Jeney', Annamaria Gazdag', Annamaria Erdei', \\ Monika Katko', Domonkos M Nagy', Bernadett Ujhelyí2, Zita Steiber2, \\ Ferenc Gyory33, Eszter Berta' and Endre V Nagy'
}

1Division of Endocrinology, Department of Internal Medicine, Faculty of Medicine, University of Debrecen, Debrecen, Hungary

2Department of Ophthalmology, Faculty of Medicine, University of Debrecen, Debrecen, Hungary

${ }^{3}$ Department of Surgery, Faculty of Medicine, University of Debrecen, Debrecen, Hungary
Correspondence should be addressed to E V Nagy Email

nagy@internal.med.unideb.hu

\begin{abstract}
During the course of Graves' orbitopathy (GO), orbital fibroblasts are exposed to factors that lead to proliferation and extracellular matrix (ECM) overproduction. Increased levels of tissue plasminogen activator inhibitor type 1 (PAI-1 (SERPINE1)) might promote the accumulation of ECM components. PAI-1 expression is regulated by cell density and various cytokines and growth factors including transforming growth factor $\beta$ (TGF- $\beta$ ). We examined the effects of increasing cell densities and TGF- $\beta$ on orbital fibroblasts obtained from GO patients and controls. Responses were evaluated by the measurement of proliferation, PAI-1 expression, and ECM production. There was an inverse correlation between cell density and the per cell production of PAI-1. GO orbital, normal orbital, and dermal fibroblasts behaved similarly in this respect. Proliferation rate also declined with increasing cell densities. Hyaluronan (HA) production was constant throughout the cell densities tested in all cell lines. In both GO and normal orbital fibroblasts, but not in dermal fibroblasts, TGF- $\beta$ stimulated PAI- 1 production in a cell density-dependent manner, reaching up to a five-fold increase above baseline. This has been accompanied by increased HA secretion and pericellular HA levels at high cell densities. Increasing cell density is a negative regulator of proliferation and PAI-1 secretion both in normal and GO orbital fibroblasts; these negative regulatory effects are partially reversed in the presence of TGF- $\beta$. Cell density-dependent regulation of PAI-1 expression in the orbit, together with the local cytokine environment, may have a regulatory role in the turnover of the orbital ECM and may contribute to the expansion of orbital soft tissue in GO.
\end{abstract}

\section{Key Words}

- Graves' orbitopathy

- orbital fibroblasts

- PAl-1

- hyaluronan

- cell density

- TGF- $\beta$
Journal of Endocrinology (2016) 229, 187-196

\section{Introduction}

Graves' orbitopathy (GO) is the extrathyroidal manifestation of Graves' disease characterized by an autoimmune inflammation resulting in an increased volume of the orbital connective tissue and enlargement of the extraocular muscles (Bahn 2010, Wang \& Smith
2014). Orbital fibroblasts (OFs) are the main target cells in GO due to their expression of autoantigens specific to GO (Otto et al. 1996, Bahn 2010, Wang \& Smith 2014). Macrophages, $\mathrm{T}$ and $\mathrm{B}$ lymphocytes, and mast cells infiltrate the orbit and activate the OFs (Bahn 2010).

Published by Bioscientifica Ltd 
Cytokine-dependent activation of OFs augments the inflammatory and autoimmune processes and accounts for orbital tissue remodeling (Smith 2005).

Altered synthesis and degradation of extracellular matrix (ECM) components by activated OFs play a key role in the pathogenesis of GO (Smith 2005). Hyaluronan (HA) is the major ECM glycosaminoglycan, a high-molecularweight polysaccharide with essential role in cell-ECM and cell-cell interactions. HA is synthesized at the plasma membrane by three isoenzymes named hyaluronan synthase (HAS) 1, 2, and 3, which possess different biochemical properties (Vigetti et al. 2014). HA has a high turnover rate; hyaluronidase (HYAL) 1 and 2 are the major hyaluronidases expressed in human tissues (Girish \& Kemparaju 2007). HA is retained as a pericellular coat after its synthesis, anchored to the cell surface via the synthase enzyme or through binding to a surface receptor, and certain amount cleaved by hyaluronidase is released from the pericellular matrix and incorporated as an integral component of the ECM. Alterations in this process could affect the physiological role of HA in the surrounding tissue (Monslow et al. 2015). In GO, OFs secrete large amounts of HA in response to, as of now, only partially characterized cytokines and antibodies (Bahn 2010). Due to its hydrophilic nature, HA accumulation accelerates expansion of the orbital connective tissues (Wang \& Smith 2014). In addition, the interaction between HA and its receptor on the surface of most immune cells is important for the infiltration of leukocytes into the inflamed tissue (DeGrendele et al. 1997).

In addition to ECM molecules, fibroblasts synthesize and secrete proteases capable of degrading the ECM (McAnulty 2007). The plasminogen activator/plasmin system and its main negative regulator, the plasminogen activator inhibitor type 1 (PAI-1 (SERPINE1)), have important roles in ECM degradation and remodeling (Smith \& Marshall 2010). PAI-1 is a single-chain glycoprotein and a member of the serine protease inhibitor family. PAI-1 inhibits tissue and urokinase-type plasminogen activators, thus inhibiting the plasminogenplasmin conversion as well as plasmin-dependent matrix metalloprotease activation. Therefore, PAI-1 is a primary regulator of plasmin-driven proteolysis of the ECM. The increased expression of PAI-1 results in ECM accumulation (Małgorzewicz et al. 2013). The expression of PAI-1 is regulated by various cytokines and growth factors including transforming growth factor $\beta$ (TGF- $\beta$ ) (Ghosh \& Vaughan 2012). Strong TGF- $\beta$ expression has been found in the orbital tissue of patients with mild and severe GO, which correlated positively with the clinical activity score (CAS) (Pawlowski et al. 2014). It has been demonstrated that OFs synthesize PAI-1, and that PAI-1 expression is up-regulated by TGF- $\beta$, interferon- $\gamma$ (IFN- $\gamma$ ), and leukoregulin (Smith et al. 1992, Cao et al. 1995, Hogg et al. 1995); however, the role of PAI-1 in the pathogenesis of GO is still unclear.

PAI-1 expression has been shown to be dependent on cell density in various cell types including human preadipocytes (Crandall et al. 1999), dermal fibroblasts (McFarland et al. 2011), and NIH/3T3 cells (Tanaka et al. 2013). Those studies revealed that PAI- 1 synthesis decreased during the process of growth toward confluency, which was consistent with the observation that PAI-1 transcription occurred during the G0 to G1 transition (Qi et al. 2006). However, it is unknown how PAI-1 expression is altered by the increased fibroblast proliferation during the course of GO.

The aim of this study is to investigate whether cell density alone or in combination with TGF- $\beta$ affected the secretion of PAI- 1 and the accumulation of the ECM component $\mathrm{HA}$ in $\mathrm{OF}$ cultures originating from normal and GO orbits.

\section{Materials and methods}

\section{Materials}

Recombinant human TGF- $\beta 1$, fetal bovine serum (FBS), Medium 199 with Earles' salts and GlutaMAX supplement, penicillin/streptomycin, Dulbecco's phosphate-buffered saline without calcium and magnesium (DPBS), trypsinEDTA solution, freezing medium, and TrypLE Express were purchased from Gibco (Thermo Fisher Scientific). DuoSet ELISA Human Serpin E1/PAI-1 Kit and DuoSet Hyaluronan Kit were purchased from R\&D Systems (R\&D Systems). Cell proliferation ELISA BrdU (colorimetric) kits were purchased from Roche (F. Hoffmann-La Roche Ltd). RNeasy Protect Cell Mini was purchased from QIAGEN (QIAGEN $\mathrm{GmbH})$. High Capacity cDNA Reverse Transcription Kit and TaqMan Gene Expression Assays were purchased from Applied Biosystems (Thermo Fisher Scientific).

\section{Tissue samples and cell cultures}

Orbital connective tissue explants were obtained from five patients (three females and two males) undergoing orbital decompression surgery for GO. The mean age of patients at the time of surgery was 45.4 (range 37-55) years. The mean duration of Graves' disease and GO was $5.6 \pm 4.2$ (range 1-11) and $3.0 \pm 2.9$

Published by Bioscientifica Ltd. 
(range 1-8) years respectively. All but one patient was in the inactive phase of GO. The patient with active GO and one patient with inactive GO were positive to thyroid-stimulating hormone (TSH) receptor antibody. Before surgery, two patients underwent thyroidectomy, two patients got radioactive iodine treatment, and all but one patient has been on antithyroid drugs for some time during the course of the disease. All patients had received corticosteroid treatment in the past, and two patients received orbital irradiation. During the last 2 months before orbital surgery, patients used only diuretics, $\beta$-blockers, thyroxine supplementation, and local measures. Patients at the time of surgery had suppressed TSH levels and high-normal thyroid hormone levels. Control normal orbital tissues (five patients: two females and three males, mean age: 63.4 years; range $47-72$ years) were obtained during surgery (enucleation) for nonorbital eye diseases, and control dermal connective tissues (three patients: two females and one male, mean age: 64.7 years; range $50-80$ years) were obtained during abdominal hernia operations from patients with no history of thyroid diseases. The study was approved by the Ethics Committee of the University of Debrecen. All patients gave their written informed consent.

Human OFs were cultured as described previously in detail by Bahn et al. (1987). Briefly, the tissues were cut into $2 \times 2 \mathrm{~mm}$ pieces and inoculated into culture dishes containing Medium 199 with Earle's salts with 20\% (v/v) FBS and penicillin-streptomycin, and cultured at $37^{\circ} \mathrm{C}, 5 \% \mathrm{CO}_{2}$, in a humidified incubator. Medium was changed every 3-4 days. After 2-3 weeks, depending on the proliferative rate of the culture, the tissue pieces were removed and the cell cultures were maintained in Medium 199 with 10\% (v/v) FBS under the same conditions. After gentle treatment using TrypLE Express dissociating reagent, cells were stored in freezing medium in liquid nitrogen until needed. The cells were studied between passages 2 and 8 .

For experiments, orbital and dermal fibroblasts were plated in 24 -well plates, in various cell densities $\left(6.24 \times 10^{4}, 3.12 \times 10^{4}, 1.56 \times 10^{4}, 7.8 \times 10^{3}, 3.9 \times 10^{3}\right.$, and $\left.1.95 \times 10^{3} \mathrm{cells} / \mathrm{cm}^{2}\right)$ in Medium 199 supplemented with $10 \%(\mathrm{v} / \mathrm{v})$ FBS. Densities of $1.56 \times 10^{4} \mathrm{cells} / \mathrm{cm}^{2}$ and above represent confluent and post-confluent cultures respectively. The cultures were synchronized with serum starvation for $24 \mathrm{~h}$ (Khammanit et al. 2008) followed by treatment with medium containing $10 \%(\mathrm{v} / \mathrm{v})$ FBS with or without TGF- $\beta(1 \mathrm{ng} / \mathrm{mL})$ for an additional $24 \mathrm{~h}$. The conditioned media were collected and centrifuged at $1000 \boldsymbol{g}$ for $5 \mathrm{~min}$ to remove any cellular debris and stored at $-20^{\circ} \mathrm{C}$ until used. All experiments were performed at least three times and carried out in triplicate.

\section{Cell proliferation assay}

Cells were treated as described above. The assay was performed in 96-well plates according to the manufacturer's instructions. Briefly, the 5-bromo-2'-deoxyuridine (BrdU) solution was added to the cell cultures and incubated for $2 \mathrm{~h}$. After removing the medium, cells were fixed using FixDenat solution for $30 \mathrm{~min}$. Then, peroxidase-conjugated anti-BrdU antibody was added for $90 \mathrm{~min}$. Finally, 3,3',5,5'-tetramethylbenzidine substrate was introduced for $10 \mathrm{~min}$, and after the addition of $2 \mathrm{~N} \mathrm{H}_{2} \mathrm{SO}_{4}$, the absorbance at $450 \mathrm{~nm}$ (reference wavelength: $620 \mathrm{~nm}$ ) was detected using a Beckman Coulter, DTX 880 Multimode Detector (Beckman Coulter Inc., Brea, CA, USA).

\section{Quantitation of PAI-1 protein and HA}

Secreted PAI-1 protein and HA levels in cell culture supernatants were measured by using DuoSet ELISA Human Serpin E1/PAI-1 Kit and DuoSet Hyaluronan Kit respectively. For pericellular HA measurement, cells were washed twice with DPBS and treated with $0.05 \%$ (w/v) trypsin-EDTA solution at $37^{\circ} \mathrm{C}$ for $20 \mathrm{~min}$, and the reaction was stopped by addition of FBS $(10 \% \mathrm{v} / \mathrm{v}$ final concentration). After centrifugation at $1000 \mathrm{~g}$ for $5 \mathrm{~min}$, supernatants were used for HA determination. In each case, results were adjusted for the HA content of FBS. In all experiments, the PAI-1 and HA productions per cell were expressed as $\mathrm{ng} / 10^{5}$ cells.

\section{Real-time polymerase chain reactions (RT-PCR)}

The supernatants were removed and cells were washed twice with DPBS. RNeasy Protect Cell Mini Kit was used for the isolation of RNA from cells. We used the QIAcube robotic workstation (QIAGEN) for the isolation of RNA. The purified RNA samples were reverse transcribed by High Capacity cDNA Reverse Transcription Kit. The TaqMan Gene Expression Assays was used for the detection of the expression of PAI-1, HAS1, HAS2, HAS3, HYAL1, HYAL2, and glyceraldehyde 3-phosphate dehydrogenase (GAPDH) (assay IDs: SERPINE1-Hs01126603_m1, HAS1-Hs00987418_m1, HAS2-Hs00193435_m1, HAS3-Hs00193436, HYAL1Hs00201046_m1, HYAL2-Hs01117343_g1, and GAPDHHs02758991_g1 respectively). The reactions were performed by the StepOnePlus Real-time PCR System

Published by Bioscientifica Ltd. 
(Applied Biosystems). Results were normalized to GAPDH mRNA levels by the $\Delta \mathrm{C}_{\mathrm{T}}$ method.

\section{Statistical analysis}

Statistical analysis was performed using the STATISTICA 12 software (Statsoft Inc. Tulsa, OK, USA). Data are expressed as mean \pm S.E.M. Repeated measures analysis of variance (ANOVA) with density as the within-subjects factor and origin of fibroblasts (dermal fibroblasts, normal OFs, and GO OFs) as between-subjects factor and LSD post hoc analysis were performed to evaluate the differences. Correlation analysis was performed to study the relationship between continuous variables. The level of statistical significance was set at $P<0.05$.

\section{Results}

Dermal fibroblasts, normal OFs, and GO OFs secreted comparable amounts of PAI-1 protein at each density. Cell culture synchronization by serum starvation for $24 \mathrm{~h}$ before experiments resulted in slightly but significantly higher amounts of secreted PAI- 1 at the end of 24-h tests in medium re-supplemented with serum and led to less variance between repetitions (data not shown). PAI-1 secreted by individual cells (expressed as ng/10 cells) decreased significantly $(P<0.000001)$ with increasing cell densities (Fig. 1A); however, the origin of fibroblasts was not a significant factor; normal OFs and GO OFs behaved similarly in this respect. RT-PCR confirmed that PAI-1 mRNA level decreased in parallel with PAI-1 protein concentration with increasing cell density $(P<0.0001)$ (Fig. 2A). PAI-1 mRNA expression was different in cell lines with different origin $(P<0.01)$ : in descending order, dermal fibroblasts, normal OFs, and GO OFs (dermal fibroblasts vs normal OFs, $P<0.01$; dermal fibroblasts vs GO OFs, $P<0.001$; normal OFs vs GO OFs, $P=0.03$ ).

HA secretion into the medium and pericellular HA levels did not show cell density-dependent behavior ( $P=0.6$ and $P=0.2$ respectively), and the origin of fibroblasts was the main predictor of $\mathrm{HA}$ synthesis $(P<0.001)$ (Fig. 1B and C). Post hoc analysis showed that dermal fibroblasts secreted significantly higher amounts of HA than OFs (dermal fibroblasts vs normal OFs, $P<0.01$; dermal fibroblasts vs GO OFs, $P<0.001)$. In OFs, higher HA producers ( $>500 \mathrm{ng} / 10^{5}$ cells) only occur among normal OFs (two out of five), and lower HA producers $\left(<300 \mathrm{ng} / 10^{5}\right.$ cells) only occur among GO OFs (three out of five). Similar results were found in pericellular HA
A

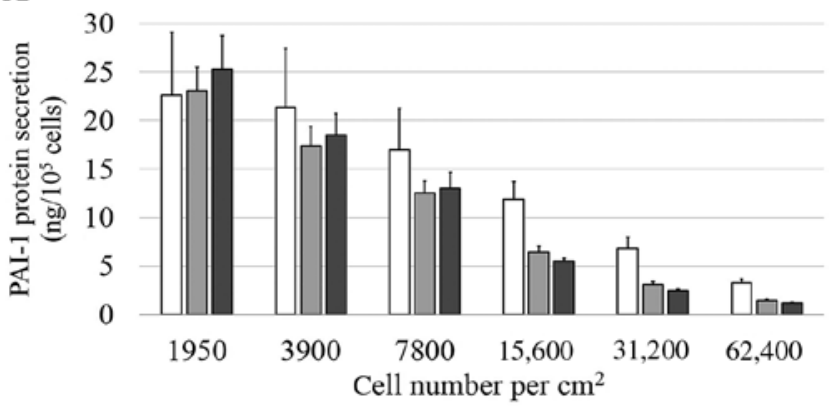

B
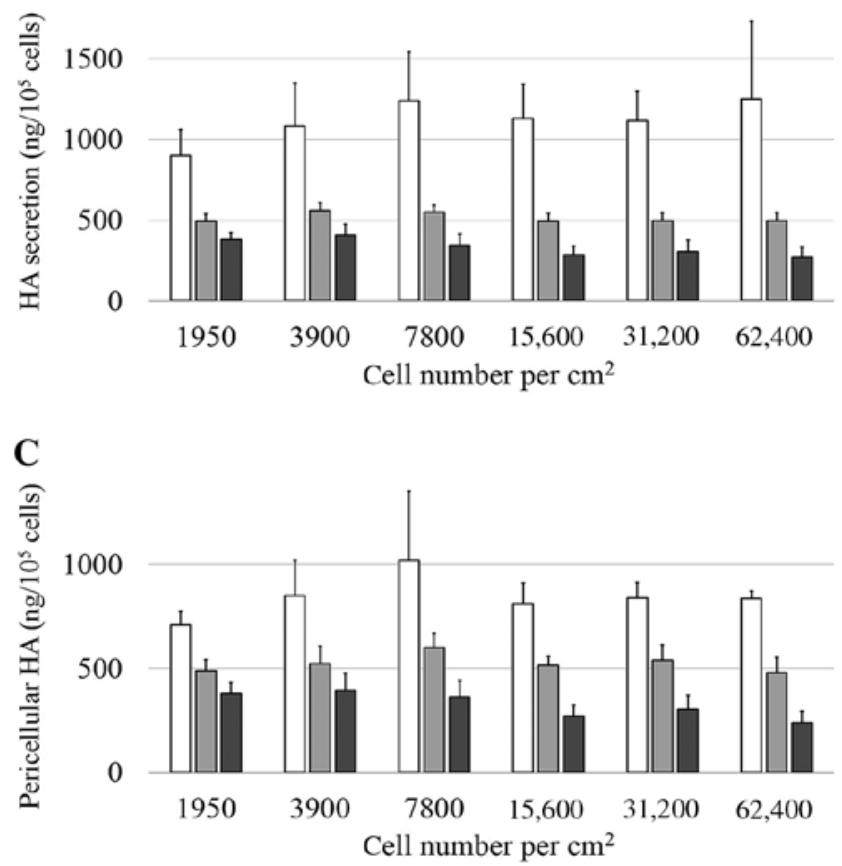

D

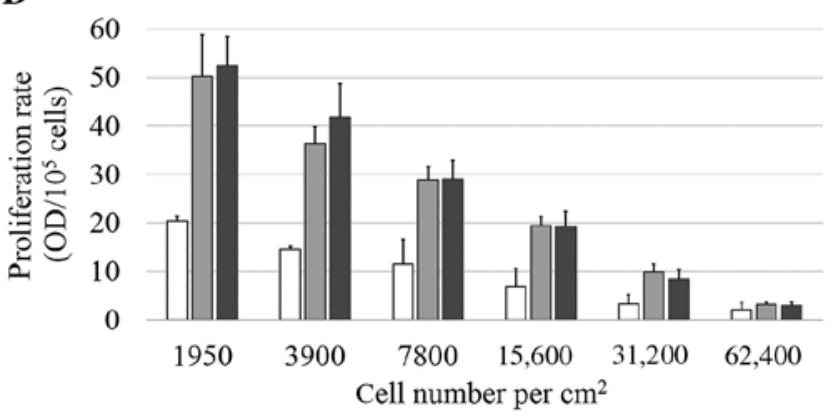

Dermal fibroblasts $\square$ Control OFs $\square$ GO OFs

\section{Figure 1}

Influence of cell density on (A) PAI-1 secretion, (B) hyaluronan (HA) secretion, (C) pericellular HA level, and (D) proliferation rate of dermal fibroblasts, normal orbital fibroblasts (OFs), and Graves' orbitopathy orbital fibroblasts (GO OFs). Results shown are the mean \pm S.E.M. 
levels (dermal fibroblasts vs normal OFs, $P=0.013$; dermal fibroblasts vs GO OFs, $P<0.001$ ), although there was a tendency toward lower pericellular HA in GO OFs than in normal OFs $(P=0.06)$. We found significant positive correlation between HA released into the medium and HA retained in the pericellular matrix (dermal fibroblasts: $r=0.72, P<0.01$; normal OFs: $r=0.77, P<0.00001$; GO OFs: $r=0.97, P<0.000001)$. Results of the RT-PCR showed that HAS1 and HAS3 expressions were in the same order of magnitude, whereas HAS2 was the predominant HAS enzyme in all cell lines studied (Fig. 2B, C and D). The expression pattern of HAS enzymes was different in fibroblasts with distinct types of origin. Dermal fibroblasts had higher expression levels of HAS1 and HAS2 mRNA than OFs (dermal fibroblasts vs normal OFs, $P=0.05$ and $P<0.0001$, dermal fibroblasts vs GO OFs, $P=0.02$ and $P<0.0001$, for HAS1 and HAS2, respectively), whereas OFs had higher HAS3 expression than dermal fibroblasts (dermal fibroblasts vs normal OFs, $P=0.03$, dermal fibroblasts vs
GO OFs, $P<0.0001)$. GO OFs had higher HAS3 expression than normal OFs $(P<0.001)$. The expression of HAS1 and HAS2 decreased with increasing cell density in dermal fibroblasts. The expression of HYAL1 was more diverse than the expression of HYAL2 (Fig. 2E and F). Dermal fibroblasts had the lowest HYAL1 expression, and GO OFs had lower HYAL1 expression than normal OFs (dermal fibroblasts vs normal OFs, $P<0.001$, dermal fibroblasts vs GO OFs, $P<0.01$, normal OFs vs GO OFs, $P<0.001$ ). There was a tendency for lower HYAL1 and HYAL2 expression in confluent cultures than in pre- and post-confluent cultures.

The proliferation rate of fibroblasts declined significantly $(P<0.000001)$ with increasing cell densities in all fibroblasts tested, irrespective of the site of origin (Fig. 1D). Accordingly, significant positive correlation was found between proliferation and PAI-1 secretion in all fibroblasts studied (dermal fibroblasts: $r=0.81$, $P<0.01$; normal OFs: $r=0.71, P<0.0001$; GO OFs: $r=0.70$,
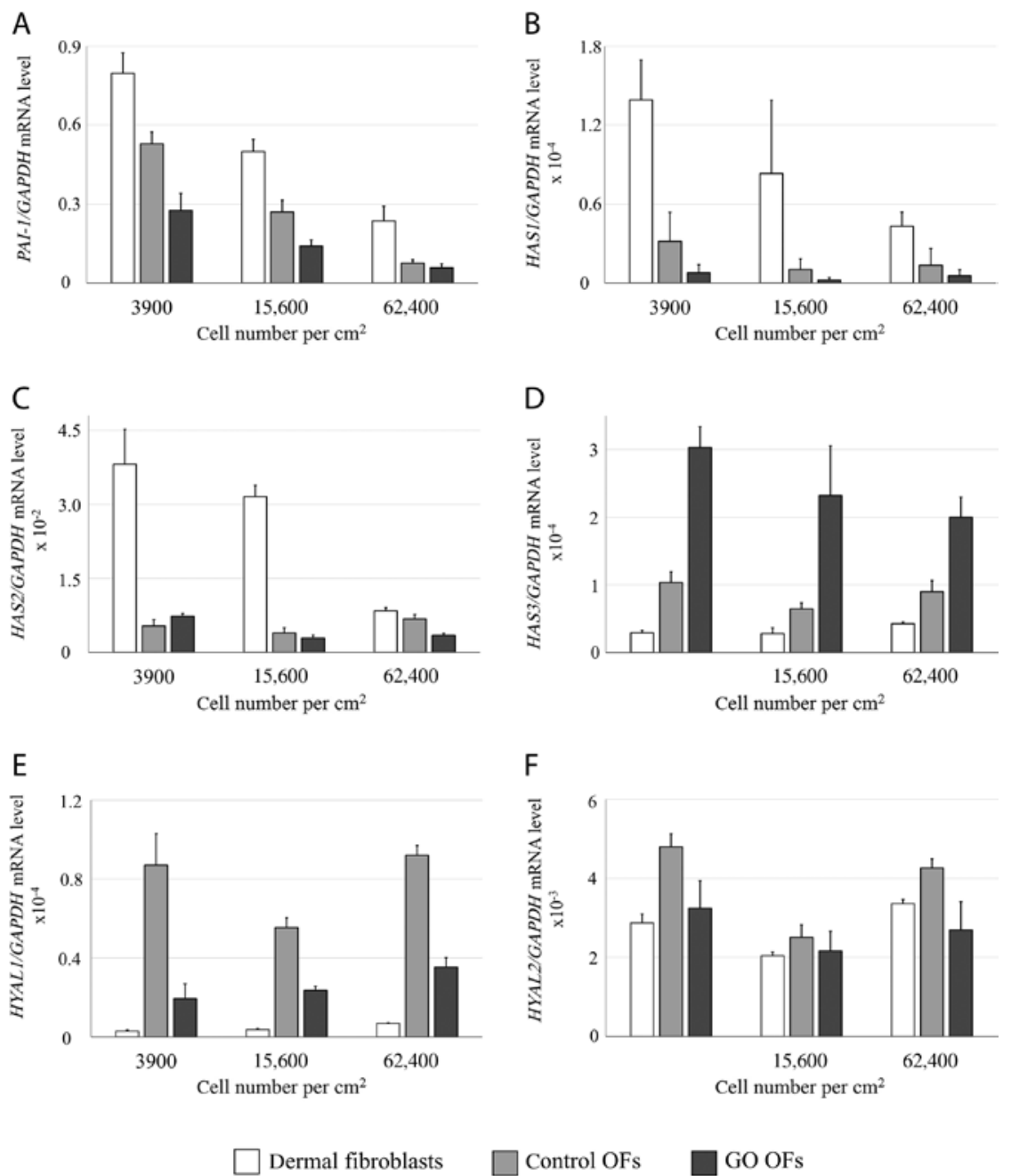

Figure 2

Influence of cell density on (A) PAI-1, (B) HAS1, (C) HAS2, (D) HAS3, (E) HYAL1, and (F) HYAL2 mRNA expression in dermal fibroblasts, normal orbital fibroblasts (OFs), and Graves' orbitopathy orbital fibroblasts (GO OFs). Results were adjusted for the expression of GAPDH. Results shown are the mean \pm S.E.M. http://joe.endocrinology-journals.org DOI: 10.1530/JOE-15-0524
(C) 2016 Society for Endocrinology Printed in Great Britain 
$P<0.0001)$. The proportion of proliferating cells was significantly higher in OFs than in dermal fibroblasts at all but one density (normal OFs vs dermal fibroblasts, $P=0.03$; GO OFs vs dermal fibroblasts, $P=0.02$ ). No differences were observed between OFs derived from normal and GO orbital connective tissues $(P=0.8)$ according to the post hoc tests.

Next, our model was completed with TGF- $\beta$ treatment. Dose-response experiments were performed in a range of $0.01-10 \mathrm{ng} / \mathrm{mL} ; 1 \mathrm{ng} / \mathrm{mL}$ TGF- $\beta$ had the maximal effect on PAI-1 secretion during the 24-h treatment, and this concentration was selected for further experiments.

At each density, TGF- $\beta$ stimulated PAI-1 secretion in all tested cell lines, irrespective of the site of origin $(P<0.000001)$. In both GO and normal OFs, but not in dermal fibroblasts, the extent of the stimulation by TGF$\beta$ strongly depended on cell density $(P<0.00001)$; more marked stimulation of PAI-1 secretion was seen with increasing densities (Fig. 3A). The same stimulation pattern was detected when PAI-1 mRNA levels were examined under the effect of TGF- $\beta$ (Fig. 4A). Thus, the PAI-1-lowering effect of high cell densities (Fig. 1A) has been partially reversed by TGF- $\beta$.

Significant stimulatory effect of TGF- $\beta$ on HA secretion into the medium was seen at the highest cell densities, irrespective of the origin of fibroblasts $(P<0.0001)$ (Fig. 3B). The same was true for pericellular HA of OFs (Fig. 3C), whereas dermal fibroblasts responded to TGF- $\beta$ with a pericellular HA rise at all densities. The positive correlation between HA in the medium and pericellular HA seen in unstimulated cultures (Fig. 1B and C) remained significant in cell cultures after $24 \mathrm{~h}$ TGF- $\beta$ treatment (dermal fibroblasts: $r=0.58, P=0.02$; normal OFs: $r=0.95, P<0.000001$; GO OFs: $r=0.89, P<0.000001)$. The expression of HAS2, HAS3, HYAL1, and HYAL2 did not changed or slightly decreased in TGF- $\beta$-treated cells (data not shown), whereas HAS1 mRNA expression increased markedly in a cell density-dependent manner $(P=0.03)$, especially in OFs (Fig. 4B).

In OF cultures, TGF- $\beta$-induced increase in PAI-1 secretion was directly proportionate to the changes of both HA secretion (normal OFs: $r=0.78, P<0.000001$; GO OFs: $r=0.56, P<0.01$ ) and pericellular HA level (normal OFs: $r=0.67, P<0.0001$; GO OFs: $r=0.73, P<0.00001$ ).

There was only a minor effect of TGF- $\beta$ on the proliferation rate (Fig. 3D), which was dependent on cell density $(P<0.01)$. A slight non-significant increase was only observed at the highest density of orbital cultures ( $P=0.051$ in normal and $P=0.22$ in GO OFs). At other densities, mild inhibitory effect of TGF- $\beta$ was detected (most pronounced in dermal cultures at the lowest density
A

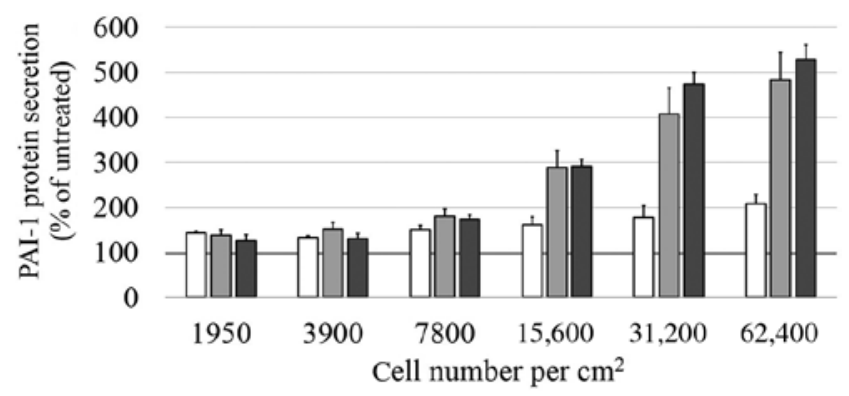

B

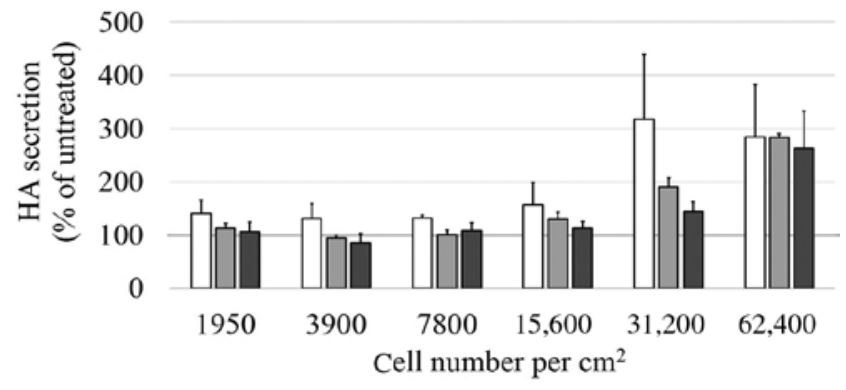

C

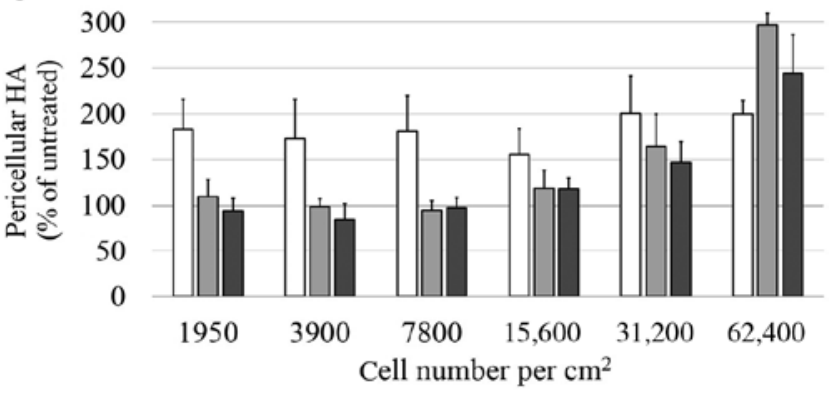

D

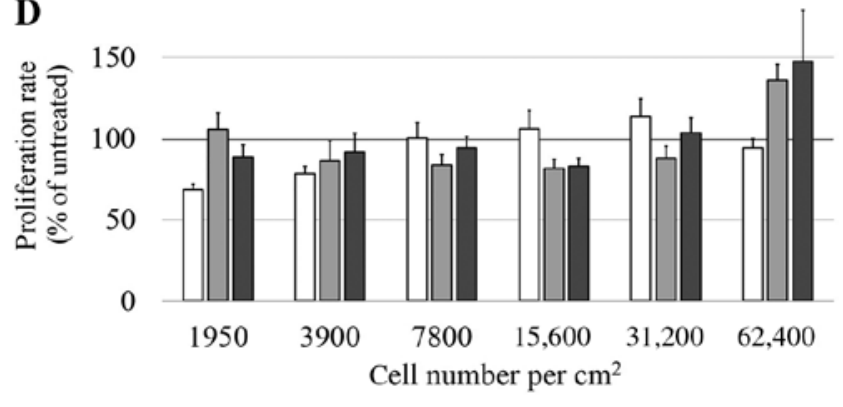

Dermal fibroblasts $\square$ Control OFs

$\square$ GO OFs

Figure 3

Influence of TGF- $\beta$ treatment ( $1 \mathrm{ng} / \mathrm{mL}$ ) on (A) PAl-1 secretion, (B) hyaluronan (HA) secretion into the medium, (C) pericellular HA levels, and (D) proliferation rate at increasing cell densities. The $100 \%$ line represents the respective untreated cultures. Results are shown as $\%$ of untreated (mean \pm S.E.M.).

Published by Bioscientifica Ltd. 
A

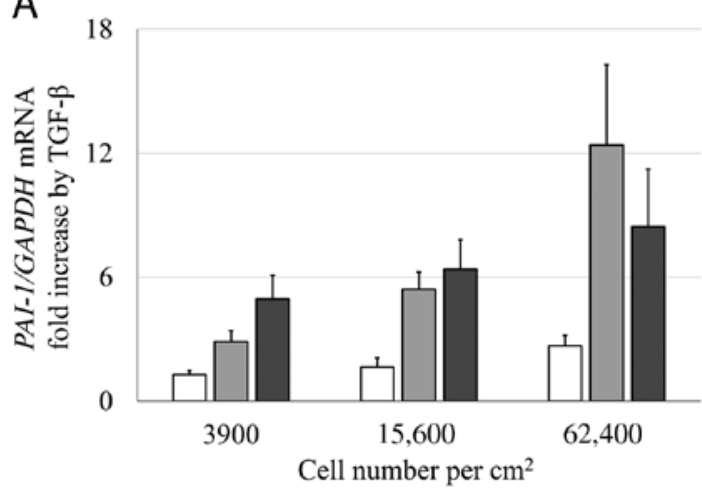

B

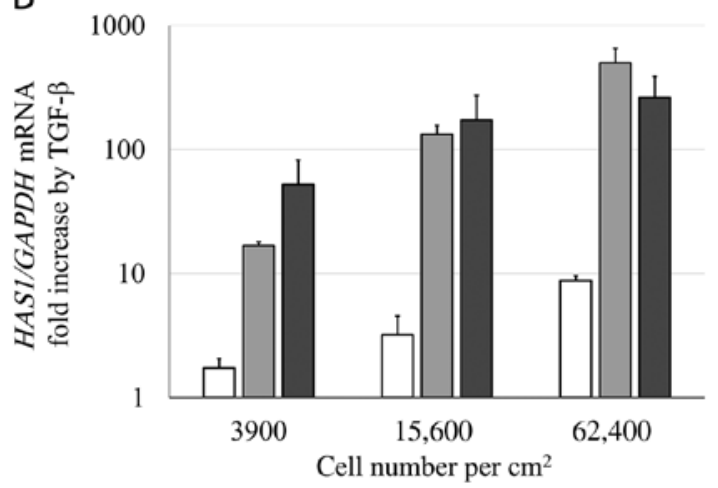

Dermal fibroblasts

Control OFs

GO OFs

Figure 4

Influence of TGF- $\beta$ treatment ( $1 \mathrm{ng} / \mathrm{mL}$ ) on (A) PAl-1 and (B) HAS1 mRNA expression at increasing cell densities. Results are shown as fold increase relative to the respective untreated cultures (mean \pm S.E.M.).

with $70 \%$ of untreated, $P<0.01$, and in orbital cultures $82 \%$ of untreated, $P=0.04)$.

\section{Discussion}

Orbital fibroblasts are considered to be the primary targets of the autoimmune process in GO, activated by cytokines released by immune cells infiltrating the orbital connective tissue (Bahn 2010, van Steensel et al. 2012). Stimulated OFs deposit ECM components and proliferate in an unregulated manner (Wang \& Smith 2014). HA is the major overproduced glycosaminoglycan in the GO orbit (Hufnagel et al. 1984, Smith et al. 1989, Bahn 2010). HA accumulation in the orbital connective tissue causes edematic swelling (Natt \& Bahn 1997) and facilitates inflammatory cell infiltration (Guo et al. 2011, Evanko et al. 2012), thereby promoting disease progression. ECM remodeling requires proteolytic enzyme activity (Lu et al. 2011). The plasminogen activator system plays a key role in ECM remodeling in many physiological and pathophysiological processes (Mignatti \& Rifkin 1993), as PAI-1 is the main negative regulator of the conversion of plasminogen to plasmin; inhibits fibrinolysis and plasmin-dependent pericellular proteolysis (Ghosh \& Vaughan 2012); modulates cellular adhesion, migration, and wound healing. As a consequence, the balance between ECM synthesis and degradation is regulated, to a great extent, by PAI-1. However, cell-cell contacts regulate proliferation and PAI-1 expression in non-transformed cells (Comi et al. 1995, Tanaka et al. 2013). During the course of GO, overproduction of HA creates a loose, highly hydrated environment, which has an impact on cell-cell contacts and cell-ECM interactions.

In this study, we have shown that cell density is a negative regulator of both proliferation and PAI-1 production in OFs, regardless of whether they are derived from normal or GO orbital tissue. Contact inhibition of proliferation is typical of non-transformed cells (Küppers et al. 2010) and is considered to be continuously active, regulating cell proliferation and organ size in adult tissues (Zeng \& Hong 2008). Therefore, we have hypothesized that confluent cultures correspond to the healthy orbit, whereas pre-confluent cultures represent the expanding, high ECM orbital tissue with higher fibroblast proliferation rate. We found that OFs, both from control and GO orbits, had higher proliferative capacity than dermal fibroblasts (Fig. 1D). This means that OF cultures are characterized by higher cell turnover compared with dermal fibroblasts. Others made similar observations under the same conditions in confluent cultures of OFs (Heufelder \& Bahn 1994). In our experiments, a progressive transcriptionally regulated reduction in PAI-1 synthesis with increasing cell densities was detected using fibroblasts of both dermal and orbital origin; PAI-1 synthesis per cell was inversely proportional to cell density. This is in agreement with similar studies in non-orbital cultures (Crandall et al. 1999, Tanaka et al. 2013). However, we are the first to show that OFs behave in the same manner. We assume that the growth state of OFs at different cell densities is the main determinant of PAI-1 expression. Elevated PAI-1 synthesis during G0 to G1 transition maintains a supporting scaffold for proliferation by limiting pericellular proteolysis. It was found in human keratinocytes that a dynamic occupancy of the E box site in the PE2 region of PAI-1 gene promoter by upstream stimulatory factor (USF) subtypes (USF1 vs USF2) determine the transcriptional status of the PAI-1 gene in quiescent versus cycling cells (Qi et al. 2006). Further studies are needed to confirm whether these

Published by Bioscientifica Ltd. 
transcription factors play a role in the proliferation ratedependent PAI-1 expression of OFs.

We assumed that TGF- $\beta$ may be one of the cytokines which are responsible for the connective tissue changes in the orbit. TGF- $\beta$ is known to transcriptionally regulate cell growth, motility, matrix remodeling, and pericellular proteolytic activity (Samarakoon et al. 2013); TGF$\beta$ is also known to stimulate PAI-1 transcription and to up-regulate the expressions of certain genes that encode elements of the ECM, such as fibronectin, collagen I, and proteoglycans in non-orbital tissues (Matrisian \& Hogan 1990, Wight \& Potter-Perigo 2011). Furthermore, TGF- $\beta$ has been shown to be present in the orbits of GO patients (Pawlowski et al. 2014). Indeed, we found that TGF- $\beta$ was a potent stimulator of PAI-1 synthesis at all densities in OFs, resulting in up to a fivefold PAI-1 increase above baseline at high cell densities (Fig. 3A). The cell density-dependent stimulation of PAI-1 expression by TGF- $\beta$ may occur due to the interference or cooperativity of transcription factors (Samarakoon \& Higgins 2008). Only mild and nondensity-dependent effect was seen in dermal fibroblasts (Fig. 3A). We think that the high PAI-1 concentration in the GO orbit acts toward increased matrix stability, which may contribute to matrix expansion.

Enhanced HA synthesis was described in OFs cultured in serum-free medium with TGF- $\beta$ (Wang et al. 2005, Guo et al. 2011). We found that under basic circumstances, HA production per cell did not show a cell density-dependent pattern but was highly dependent on the origin of fibroblasts (Fig. 1B and C). This was supported by the different expression patterns of HAS enzymes in the cell lines with different origins. The three HAS isoforms have distinct enzymatic properties, such as rate of synthesis (HAS1 < HAS2 < HAS3), produced HA size (HAS1 and HAS3, 200-2000 kDa; HAS2 over $2000 \mathrm{kDa}$ ), and capability for retaining HA in the pericellular coat (HAS1 overexpression leads to smaller pericellular coat); however, changes in the transcriptional level of HAS do not always correlate with changes in the HA secretion (Itano \& Kimata 2002). During the turnover of HA, HYAL2 initiates the degradation of $\mathrm{HA}$ at the cell surface to smaller chains, which are then further degraded by HYAL1 (Girish \& Kemparaju 2007). Despite the higher expression of the HAS3, the isoform with highest activity, and lower expression of HYAL1, we observed lower HA production of GO OFs compared with normal OFs, an observation similar to that of others (Krieger \& Gershengorn 2014). When exposed to TGF- $\beta$, the same cells responded with increased HA secretion at high cell densities, in parallel with PAI-1 rise (Fig. 3B and C). We confirmed that TGF- $\beta$ treatment up-regulates
HAS1 mRNA expression. Elevated HA synthesis induced by HAS1 overexpression is known to increase HA cable formation and promote HA-dependent monocyte binding in vascular smooth muscle cells (Wilkinson et al. 2006).

From the point of disease course, the matrix overproducing responses of OFs to TGF- $\beta$ at high cell densities may be detrimental in GO. HA overproduction can diminish contact inhibition and lead to elevated proliferation (Itano et al. 2002). HA increases PAI-1 expression in a concentration-dependent manner in human vascular smooth muscle cells (Marutsuka et al. 1998) and a positive correlation exists between HA and PAI-1 produced by human aortic endothelial cells incubated with C-reactive protein (Devaraj et al. 2009). In human umbilical vein endothelial cells, high-molecular-weight HA induces activation of the TGF- $\beta$ receptor I and expression of PAI-1 (Park et al. 2012). In combination with these previous findings, our data suggest that the TGF- $\beta$-induced HA secretion at high cell densities may facilitate the cell densitydependent PAI-1 stimulation in OFs.

Based on our results, contact inhibition is an important negative regulator of PAI-1 synthesis in OFs. High proliferation rate is associated with high PAI-1 synthesis (Fig. 1A and D). As HA production of OFs did not depend on contact inhibition and/or proliferation, its excessive production in GO is most probably under the influence of locally produced cytokines. OFs may respond to certain cytokines by elevated HA production and increased proliferation; we found that TGF- $\beta$ had such effect at high cell densities. HA accumulation provides a stimulating environment for further fibroblast proliferation and leukocyte infiltration (Wight \& Potter-Perigo 2011). Our results show that the diminution of PAI-1 synthesis caused by increasing cell density is partially reversed by TGF- $\beta$ (compare Figs $1 \mathrm{~A}$ and $3 \mathrm{~A}$ ). From the point of the pathogenesis of $\mathrm{GO}$, it is remarkable that PAI-1 can directly promote the infiltration of macrophages and $\mathrm{T}$ cells (Samarakoon et al. 2013). However, the plasminogenplasmin conversion decreases; therefore, the degradation of ECM is also reduced. The ECM stabilization by PAI-1 and, as of now, unidentified factors may alter local cytokine levels by trapping cytokines and further influencing the course of GO. The ability of PAI-1 to inhibit the conversion of the latent form of TGF- $\beta$ to its active form (Ghosh \& Vaughan 2012) may act in the opposite direction.

The data presented here are preliminary and may not be related to the initiating factors of orbital autoimmunity. Connective tissue expansion is most probably several steps down from the early immune regulatory derailment

Published by Bioscientifica Ltd 
of the autoimmune process. However, connective tissue expansion is a major contributor to disease outcome, and therapeutic interventions that could interfere with ECM overproduction may have a beneficial effect in GO.

Here, we have shown for the first time that increasing cell density is a negative regulator of both proliferation and PAI-1 secretion in OFs, regardless of whether they are derived from normal or GO orbital tissues, and these negative regulatory effects are partially inhibited in the presence of TGF- $\beta$. We conclude that TGF- $\beta$ is a potent inducer of PAI- 1 and HA expression in OFs in culture. This effect of TGF- $\beta$ on PAI- 1 synthesis is specific to fibroblasts of orbital origin. As both GO and normal OFs responded the same way to TGF- $\beta$, we assume that it is rather the presence of immune cells and cytokines in the GO orbits, than any inherent difference between GO and non-GO orbital tissues, that contributes to the development of the disease in GO.

\section{Declaration of interest}

The authors declare that there is no conflict of interest that could be perceived as prejudicing the impartiality of the research reported.

\section{Funding}

This work was supported by the Hungarian National Research, Development and Innovation Office - NKFIH, grant number: K105733, and by the University of Debrecen, Faculty of Medicine Research Fund (Bridging Fund). E G was supported by TÁMOP-4.2.2.B-15/1/KONV-20150001 project that is co-financed by the European Union and the European Social Fund

\section{References}

Bahn RS 2010 Graves' ophthalmopathy. New England Journal of Medicine 362 726-738. (doi:10.1056/NEJMra0905750)

Bahn RS, Gorman CA, Woloschak GE, David CS, Johnson PM \& Johnson CM 1987 Human retroocular fibroblasts in vitro: a model for the study of Graves' ophthalmopathy. Journal of Clinical Endocrinology and Metabolism 65 665-670. (doi:10.1210/jcem-65-4-665)

Cao HJ, Hogg MG, Martino LJ \& Smith TJ 1995 Transforming growth factor-beta induces plasminogen activator inhibitor type-1 in cultured human orbital fibroblasts. Investigative Ophthalmology \& Visual Science 36 1411-1419.

Comi P, Chiaramonte R \& Maier JA 1995 Senescence-dependent regulation of type 1 plasminogen activator inhibitor in human vascular endothelial cells. Experimental Cell Research 219 304-308. (doi:10.1006/excr.1995.1232)

Crandall DL, Quinet EM, Morgan GA, Busler DE, McHendry-Rinde B \& Kral JG 1999 Synthesis and secretion of plasminogen activator inhibitor-1 by human preadipocytes. Journal of Clinical Endocrinology and Metabolism 84 3222-3227. (doi:10.1210/jcem.84.9.5987)

DeGrendele HC, Estess P \& Siegelman MH 1997 Requirement for CD44 in activated $\mathrm{T}$ cell extravasation into an inflammatory site. Science $\mathbf{2 7 8}$ 672-675. (doi:10.1126/science.278.5338.672)
Devaraj S, Yun JM, Adamson G, Galvez J \& Jialal I 2009 C-reactive protein impairs the endothelial glycocalyx resulting in endothelial dysfunction. Cardiovascular Research 84 479-484. (doi:10.1093/cvr/ cvp249)

Evanko SP, Potter-Perigo S, Bollyky PL, Nepom GT \& Wight TN 2012 Hyaluronan and versican in the control of human T-lymphocyte adhesion and migration. Matrix Biology 31 90-100. (doi:10.1016/j. matbio.2011.10.004)

Ghosh AK \& Vaughan DE 2012 PAI-1 in tissue fibrosis. Journal of Cellular Physiology 227 493-507. (doi:10.1002/jcp.22783)

Girish KS \& Kemparaju K 2007 The magic glue hyaluronan and its eraser hyaluronidase: a biological overview. Life Sciences 80 1921-1943. (doi:10.1016/j.lfs.2007.02.037)

Guo N, Woeller CF, Feldon SE \& Phipps RP 2011 Peroxisome proliferatoractivated receptor gamma ligands inhibit transforming growth factor-beta-induced, hyaluronan-dependent, $\mathrm{T}$ cell adhesion to orbital fibroblasts. Journal of Biological Chemistry 286 18856-18867. (doi:10.1074/jbc.M110.179317)

Heufelder AE \& Bahn RS 1994 Modulation of Graves' orbital fibroblast proliferation by cytokines and glucocorticoid receptor agonists Investigative Ophthalmology \& Visual Science 35 120-127.

Hogg MG, Evans CH \& Smith TJ 1995 Leukoregulin induces plasminogen activator inhibitor type 1 in human orbital fibroblasts. American Journal of Physiology 269 C359-C366.

Hufnagel TJ, Hickey WF, Cobbs WH, Jakobiec FA, Iwamoto T \& Eagle RC 1984 Immunohistochemical and ultrastructural studies on the exenterated orbital tissues of a patient with Graves' disease. Ophthalmology 91 1411-1419. (doi:10.1016/S0161-6420(84)34152-5)

Itano N \& Kimata K 2002 Mammalian hyaluronan synthases. International Union of Biochemistry and Molecular Biology: Life $\mathbf{5 4}$ 195-199. (doi:10.1080/15216540214929)

Itano N, Atsumi F, Sawai T, Yamada Y, Miyaishi O, Senga T, Hamaguchi M \& Kimata K 2002 Abnormal accumulation of hyaluronan matrix diminishes contact inhibition of cell growth and promotes cell migration. PNAS 99 3609-3614. (doi:10.1073/pnas.052026799)

Khammanit R, Chantakru S, Kitiyanant Y \& Saikhun J 2008 Effect of serum starvation and chemical inhibitors on cell cycle synchronization of canine dermal fibroblasts. Theriogenology $\mathbf{7 0}$ 27-34. (doi:10.1016/j.theriogenology.2008.02.015)

Krieger CC \& Gershengorn MC 2014 A modified ELISA accurately measures secretion of high molecular weight hyaluronan (HA) by Graves' disease orbital cells. Endocrinology 155 627-634. (doi:10.1210/ en.2013-1890)

Küppers M, Ittrich C, Faust D \& Dietrich C 2010 The transcriptional programme of contact-inhibition. Journal of Cellular Biochemistry 110 1234-1243. (doi:10.1002/jcb.22638)

Lu P, Takai K, Weaver VM \& Werb Z 2011 Extracellular matrix degradation and remodeling in development and disease. Cold Spring Harbor Perspectives in Biology 3 1-24. (doi:10.1101/cshperspect. a005058).

Malgorzewicz S, Skrzypczak-Jankun E \& Jankun J 2013 Plasminogen activator inhibitor-1 in kidney pathology. International Journal of Molecular Medicine 31 503-510. (doi:10.3892/ijmm.2013.1234)

Marutsuka K, Woodcock-Mitchell J, Sakamoto T, Sobel BE \& Fujii S 1998 Pathogenetic implications of hyaluronan-induced modification of vascular smooth muscle cell fibrinolysis in diabetes. Coronary Artery Disease 9 177-184. (doi:10.1097/00019501-199809040-00002)

Matrisian LM \& Hogan BL 1990 Growth factor-regulated proteases and extracellular matrix remodeling during mammalian development. Current Topics in Developmental Biology 24 219-259. (doi:10.1016/ S0070-2153(08)60089-7)

McAnulty RJ 2007 Fibroblasts and myofibroblasts: their source, function and role in disease. International Journal of Biochemistry and Cell Biology 39 666-671. (doi:10.1016/j.biocel.2006.11.005)

McFarland KL, Glaser K, Hahn JM, Boyce ST \& Supp DM 2011 Culture medium and cell density impact gene expression in normal skin and

Published by Bioscientifica Ltd. 
abnormal scar-derived fibroblasts. Journal of Burn Care \& Research 32 498-508. (doi:10.1097/BCR.0b013e3182223cb1)

Mignatti P \& Rifkin DB 1993 Biology and biochemistry of proteinases in tumor invasion. Physiological Reviews 73 161-195.

Monslow J, Govindaraju P \& Puré E 2015 Hyaluronan-a functional and structural sweet spot in the tissue microenvironment. Frontiers in Immunology 6 231. (doi:10.3389/fimmu.2015.00231)

Natt N \& Bahn RS 1997 Cytokines in the evolution of Graves' ophthalmopathy. Autoimmunity 26 129-136. (doi:10.3109/08916939709003857)

Otto EA, Ochs K, Hansen C, Wall JR \& Kahaly GJ 1996 Orbital tissue-derived T lymphocytes from patients with Graves' ophthalmopathy recognize autologous orbital antigens. Journal of Clinical Endocrinology and Metabolism 81 3045-3050. (doi:10.1210/ jc.81.8.3045)

Park D, Kim Y, Kim H, Kim K, Lee YS, Choe J, Hahn JH, Lee H, Jeon J, Choi C, et al. 2012 Hyaluronic acid promotes angiogenesis by inducing RHAMM-TGF $\beta$ receptor interaction via CD44-PKCd. Molecules and Cells 33 563-574. (doi:10.1007/s10059. 012-2294-1)

Pawlowski P, Reszec J, Eckstein A, Johnson K, Grzybowski A, Chyczewski L \& Mysliwiec J 2014 Markers of inflammation and fibrosis in the orbital fat/connective tissue of patients with Graves' orbitopathy: clinical implications. Mediators of Inflammation 2014 412158. (doi:10.1155/2014/412158)

Qi L, Allen RR, Lu Q, Higgins CE, Garone R, Staiano-Coico L \& Higgins PJ 2006 PAI-1 transcriptional regulation during the G0 $\rightarrow$ G1 transition in human epidermal keratinocytes. Journal of Cellular Biochemistry 99 495-507. (doi:10.1002/jcb.20885)

Samarakoon R \& Higgins PJ 2008 Integration of non-SMAD and SMAD signaling in TGF-beta1-induced plasminogen activator inhibitor type-1 gene expression in vascular smooth muscle cells. Thrombosis and Haemostasis 100 976-983. (doi:10.1160/TH08-05-0273)

Samarakoon R, Overstreet JM \& Higgins PJ 2013 TGF- $\beta$ signaling in tissue fibrosis: redox controls, target genes and therapeutic opportunities. Cellular Signalling 25 264-268. (doi:10.1016/j.cellsig.2012.10.003)

Smith TJ 2005 Insights into the role of fibroblasts in human autoimmune diseases. Clinical \& Experimental Immunology 141 388-397.
Smith HW \& Marshall CJ 2010 Regulation of cell signalling by uPAR. Nature Reviews Molecular Cell Biology 11 23-36. (doi:10.1038/nrm2821)

Smith TJ, Bahn RS \& Gorman CA 1989 Connective tissue, glycosaminoglycans, and diseases of the thyroid. Endocrine Reviews $\mathbf{1 0}$ 366-391. (doi:10.1210/edrv-10-3-366)

Smith TJ, Ahmed A, Hogg MG \& Higgins PJ 1992 Interferon-gamma is an inducer of plasminogen activator inhibitor type 1 in human orbital fibroblasts. American Journal of Physiology 263 C24-C29.

Tanaka S, Nakao K, Sekimoto T, Oka M \& Yoneda Y 2013 Cell densitydependent nuclear accumulation of ELK3 is involved in suppression of PAI-1 expression. Cell Structure and Function 38 145-154. (doi:10.1247/csf.13007)

van Steensel L, Paridaens D, van Meurs M, van Hagen PM, van den Bosch WA, Kuijpers RW, Drexhage HA, Hooijkaas H \& Dik WA 2012 Orbit-infiltrating mast cells, monocytes, and macrophages produce PDGF isoforms that orchestrate orbital fibroblast activation in Graves' ophthalmopathy. Journal of Clinical Endocrinology and Metabolism 97 E400-E408. (doi:10.1210/jc.2011-2697)

Vigetti D, Viola M, Karousou E, De Luca G \& Passi A 2014 Metabolic control of hyaluronan synthases. Matrix Biology 35 8-13. (doi:10.1016/j.matbio.2013.10.002)

Wang Y \& Smith TJ 2014 Current concepts in the molecular pathogenesis of thyroid-associated ophthalmopathy. Investigative Ophthalmology \& Visual Science 55 1735-1748. (doi:10.1167/iovs.14-14002)

Wang HS, Tung WH, Tang KT, Wong YK, Huang GJ, Wu JC, Guo YJ \& Chen CC 2005 TGF-beta induced hyaluronan synthesis in orbital fibroblasts involves protein kinase $\mathrm{C}$ betaII activation in vitro. Journal of Cellular Biochemistry 95 256-267. (doi:10.1002/jcb.20405)

Wight TN \& Potter-Perigo S 2011 The extracellular matrix: an active or passive player in fibrosis? American Journal of Physiology: Gastrointestinal and Liver Physiology 301 G950-G955. (doi:10.1152/ajpgi.00132.2011)

Wilkinson TS, Bressler SL, Evanko SP, Braun KR \& Wight TN 2006 Overexpression of hyaluronan synthases alters vascular smooth muscle cell phenotype and promotes monocyte adhesion. Journal of Cellular Physiology 206 378-385. (doi:10.1002/jcp.20468)

Zeng Q \& Hong W 2008 The emerging role of the hippo pathway in cell contact inhibition, organ size control, and cancer development in mammals. Cancer Cell 13 188-192. (doi:10.1016/j.ccr.2008.02.011)

Received in final form 6 March 2016

Accepted 15 March 2016

Accepted Preprint published online 15 March 2016
(C) 2016 Society for Endocrinology Printed in Great Britain 